\title{
Estágios de desenvolvimento gonadal de fêmeas do camarão-barba- ruça (Artemesia longinaris - Decapoda: Penaeidae)
}

\author{
Luiz Felipe Cestari Dumont ${ }^{2} \&$ Fernando D’'Incao $^{1}$
}

\author{
1. Depto de Oceanografia, Fundação Universidade do Rio Grande (FURG), Av. Itália, km 7, Caixa Postal 474, 96201-900 Rio \\ Grande, RS. \\ 2. Programa de Pós-Graduação em Oceanografia Biológica, FURG; bolsista CAPES.
}

\begin{abstract}
Stages of gonadal development in females of "barba-ruça" shrimp (Artemesia longinaris Decapoda, Penaeidae). The stages of gonadal development for the female of "barba-ruça" shrimp (Artemesia longinaris Bate, 1888) were characterized based on histological analysis. Four stages (immature, almost mature, ripe and spawned) were determined according to the structure and arrangement of cells in the ovary. Each stage corresponds macroscopically to a characteristic color, except stages I (immature) and IV (spawned), in which colors are very similar and can be distinguished only microscopically. The chromatic scale varies from white/translucent (stage I), neutral green (almost mature) to dark green (ripe). The mean size of cells was $56.9 \mu \mathrm{m}( \pm 3.5)$ (stage I), $127 \mu \mathrm{m}( \pm 2.6)$ (stage II) and $183 \mu \mathrm{m}( \pm 1.91)$ (stage III). The size frequency of cells was polimodal, and different cell stages were observed in ripe ovary, suggesting the occurrence of multiple spawning. The chromatic scale developed is an important tool for laboratory analysis, and can be easily used to identify the gonadal stages.
\end{abstract}

KEYWORDS. Artemesia, shrimp, reproduction, gonadal histology.

\section{INTRODUÇÃO}

O camarão barba-ruça Artemesia longinaris Bate, 1888 é endêmico das águas costeiras do oceano Atlântico Sul Ocidental, ocorrente de Atafona (Rio de Janeiro, Brasil, 21 $\left.{ }^{\circ} 37^{\prime} \mathrm{S}\right)$ até Puerto Rawson (Argentina, $43^{\circ} \mathrm{S}$ ), em uma extensão de aproximadamente 1.300 milhas náuticas (D’INCAO, 1999). É explorado comercialmente ao longo de toda a sua área de distribuição. $\mathrm{O}$ declínio das capturas e dos rendimentos da frota comercial, que tinha o camarãorosa, Farfantepenaeus paulensis (Pérez Farfante, 1967), como espécie-alvo, transformou essa pescaria em uma atividade multi-específica, buscando espécies alternativas para a manutenção da rentabilidade econômica (VALENTINI et al., 1991; D'InCAO et al., 2002). Esta situação fez com que outras espécies de camarões ganhassem maior importância comercial (VALENTINI et al., 1991), destacando-se: camarão-sete-barbas, Xiphopenaeus kroyeri (Heller, 1862); camarão-branco, Litopenaeus schmitti (Burkenroad, 1936); camarãosantana, Pleoticus muelleri (Bate, 1888) e camarãobarba-ruça, Artemesia longinaris Bate, 1888. Entre essas espécies, $P$. muelerii e A. longinaris foram as que apresentaram maior aumento percentual nas capturas em comparação com o camarão-rosa, F. paulensis e Farfantepenaeus brasiliensis (Latreille, 1817) (D'InCAO et al., 2002).

O aumento da pressão pesqueira e a importância social e econômica desse recurso geram a necessidade de que se obtenham informações para o desenvolvimento de um plano de manejo adequado. Entre essas informações, o conhecimento da dinâmica reprodutiva é uma das mais importantes, já que esse processo é responsável pela renovação do estoque. Definir os estágios de maturação gonadal e desenvolver uma escala cromática de uso prático em laboratório, que caracterize o estágio de maturação sexual da gônada feminina, é o primeiro passo no sentido de entender a dinâmica reprodutiva de $A$. longinaris.

O objetivo do estudo é caracterizar os estágios de desenvolvimento gonadal das fêmeas de $A$. longinaris, utilizando uma escala cromática, validada por cortes histológicos.

\section{MATERIAL E MÉTODOS}

A confiabilidade da escala cromática utilizada para identificar os diferentes estágios de maturação gonadal das fêmeas de $A$. longinaris foi obtida pelo exame histológico dos ovários. As gônadas femininas foram escolhidas para a análise devido ao maior tamanho e facilidade de identificação cromática em campo. Foram utilizadas fêmeas capturadas entre janeiro de 2002 e janeiro de 2003, provenientes de amostras obtidas em cruzeiros científicos e de coletas realizadas a partir da pesca artesanal no litoral do Rio Grande do Sul. A profundidade de coleta variou entre 1 e 20 metros. O material encontra-se depositado na coleção de crustáceos do Laboratório de Crustáceos Decápodos da FURG.

As fêmeas foram classificadas de acordo com o tamanho e a coloração da gônada fresca (tab. I). A cor predominante de cada estágio de maturação foi comparada com um catálogo de cores (PANTONE, 1999) para estabelecer um ponto de referência cromática. Após a classificação macroscópica, foram acondicionadas em frascos contendo fixador Bouin. A quantidade de fixador empregado correspondeu a um volume 10 vezes maior do que o volume da amostra. Os cortes histológicos foram realizados utilizando o método de impregnação em parafina, que consistiu em fixação, emblocamento em parafina, coloração e 
Tabela I. Classificação macroscópica dos estágios de desenvolvimento gonadal em fêmeas de Artemesia longinaris capturadas entre janeiro de 2002 e janeiro de 2003 no litoral do Rio Grande do Sul.

\begin{tabular}{|c|c|c|c|}
\hline Estágio & Descrição da gônada & Coloração & Foto \\
\hline I- pré-vitelogênese (imaturo) & $\begin{array}{l}\text { Indiferenciada, diâmetro } \\
\text { menor que o do intestino. }\end{array}$ & branco translúcido & \\
\hline $\begin{array}{l}\text { II- vitelogênese inicial } \\
\text { (maturação íncipiente) }\end{array}$ & $\begin{array}{l}\text { Bem visivel, ocupa grande } \\
\text { parte da cavidade dorsal } \\
\text { e cefalotórax. }\end{array}$ & $\begin{array}{l}\text { verde neutro } \\
\text { (pantone 5783) }\end{array}$ & \\
\hline III- vitelogênese final (maduro) & $\begin{array}{l}\text { Ocupa inteiramente a } \\
\text { cavidade dorsal e } \\
\text { cefalotorácica. }\end{array}$ & $\begin{array}{l}\text { verde escuro } \\
\text { (pantone 5743) }\end{array}$ & \\
\hline
\end{tabular}

montagem (Bell \& LightNer, 1988). As lâminas foram analisadas em microscópio óptico, munido de um sistema de captura de imagens. As imagens foram obtidas randomicamente para posterior medição do diâmetro dos ovócitos.

As medidas foram obtidas com o auxílio do software Image Tools 2.0, utilizando a ferramenta de medição de distâncias. Uma lâmina de um milímetro foi utilizada para a calibração da ferramenta, em aumento de 4x. Foram feitas 30 medidas de uma distância conhecida e a média foi adotada para calibrar a régua de medição do programa.

Analisaram-se 15 diferentes ovários em cada estágio, com exceção do estágio IV (desovado), no qual foram observadas apenas quatro fêmeas. O número mínimo de ovócitos medidos foi 38 e o máximo 127. As medidas foram tomadas sempre no maior diâmetro e as células escolhidas randomicamente. Os diâmetros das células foram agrupados em classes de $5 \mu \mathrm{m}$ para a análise de distribuição de freqüência por estágio de maturação. Realizaram-se análise de variância e teste de hipótese para múltiplas comparações (Tukey), visando comparar os diâmetros celulares médios entre os diferentes estágios de maturação (ZAR, 1984).

\section{RESULTADOS}

Foram identificados quatro estágios histológicos de desenvolvimento da gônada feminina, de acordo com as características das células observadas nos ovários.

No estágio I (pré-vitelogênese ou imaturo), as células mais abundantes são as oogônias (oog), que fazem parte do epitélio germinativo; nota-se o envoltório de tecido conjuntivo recobrindo o ovário, chamado de túnica conjuntiva (tc). As oogônias são células pequenas, ovaladas ou arredondadas. O núcleo esférico ocupa quase toda a célula e o citoplasma apresenta intensa basilifilia (afinidade pela hematoxilina). Essas células ocupam a porção central do ovário, formando a zona de proliferação (zp). Os ovócitos são envolvidos pelas células foliculares (cf), que são as responsáveis pelo fornecimento de nutrientes. Os ovócitos imaturos (ovI) ocupam a porção mais periférica da gônada e são caracterizados pelo citoplasma basófilo e por serem maiores do que as oogônias. Ovócitos I possuem forma arredondada ou angulada e núcleo esférico (fig. 1). O diâmetro médio dos ovócitos nesse estágio é $56,9 \mu \mathrm{m}( \pm 3,5)$ (tab. II, fig. 5).

O estágio II (vitelogênese inicial ou incipiente) é marcado pelo início da vitelogênese, quando começam a aparecer, no citoplasma, pequenos grânulos de vitelo. O núcleo é grande e esférico. O citoplasma torna-se acidófilo, adquirindo a cor rosa (eosina) quando corado por hematoxilina e eosina. Ovócitos característicos do estágio I também estão presentes (fig. 2). O diâmetro médio da célula aumenta para $127 \mu \mathrm{m}( \pm 2,6)$ (tab. II, fig. 5).

No estágio III (vitelogênese final ou maduro), os ovócitos continuam a aumentar de tamanho e o diâmetro médio é $183 \mu \mathrm{m}( \pm 1,91)$ (tab. II, fig. 5). Durante esse estágio a célula apresenta intensa vitelogênese. Nessa fase os grânulos são bem visíveis, seu tamanho aumenta e nota-se uma concentração de vitelo na região cortical do citoplasma. O núcleo perde a forma arredondada, pois a concentração de vitelo no citoplasma é tão grande que o núcleo fica total ou parcialmente recoberto. Foram encontrados ovócitos I e II simultaneamente com os ovócitos III (fig. 3).

No estágio IV (desovado), o ovário perde a organização celular, restando lacunas geradas pela liberação dos ovócitos maduros, células foliculares e grânulos de vitelo. Foram observados ovócitos em reabsorção. Em ovários neste estágio, foram verificados ovócitos nos estágios I, II e III (fig. 4).

$O$ resultado da ANOVA mostrou diferença significativa no diâmetro médio dos ovócitos (tab. II). $\mathrm{O}$ teste a posteriori de Tukey demonstrou que o tamanho médio dos ovócitos aumenta, à medida que o ovário se desenvolve.

A distribuição de freqüência do diâmetro dos ovócitos mostrou ser polimodal, sugerindo que os ovócitos são maturados progressivamente em lotes (fig. 5). A partir da verificação microscópica, foi adotado o estágio III como aquele em que as fêmeas estão aptas para reprodução. 


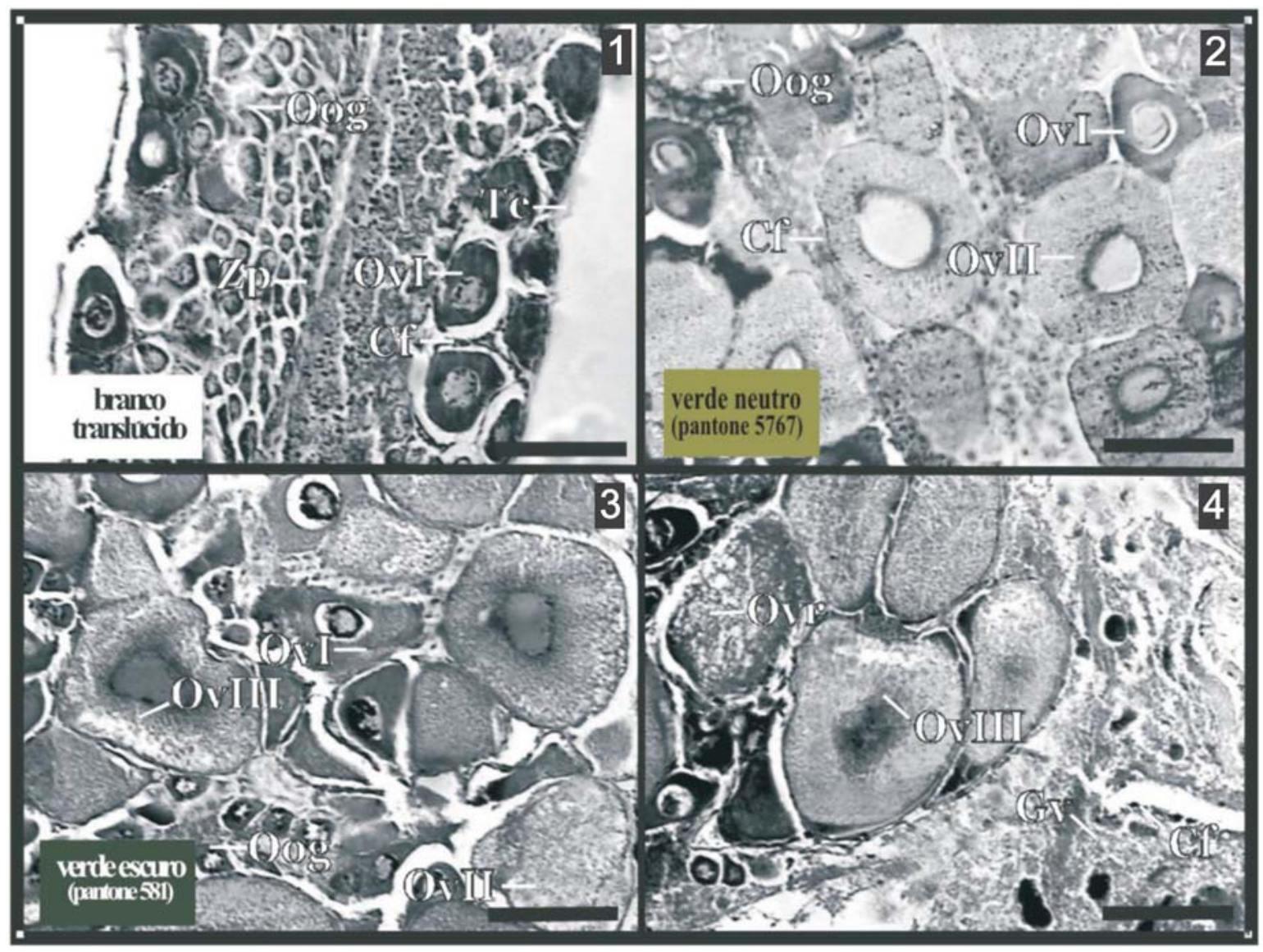

Figs. 1-4. Artemesia longinaris, gônada feminina. 1, estágio I (imaturo) de maturação; 2, estágio II (maturação incipiente); 3, estágio III (maduro); 4, estágio IV (desovado) (Cf, células foliculares; Gv, grânulos de vitelo; Oog, oogônia; Ovr, ovócito em absorção; OvI, ovócito imaturo; OvII, ovócito em vitelogênese inicial; OvIII, ovócito maduro; Tc, túnica conjuntiva; Zp, zona de proliferação) Escala $100 \mu \mathrm{m}$

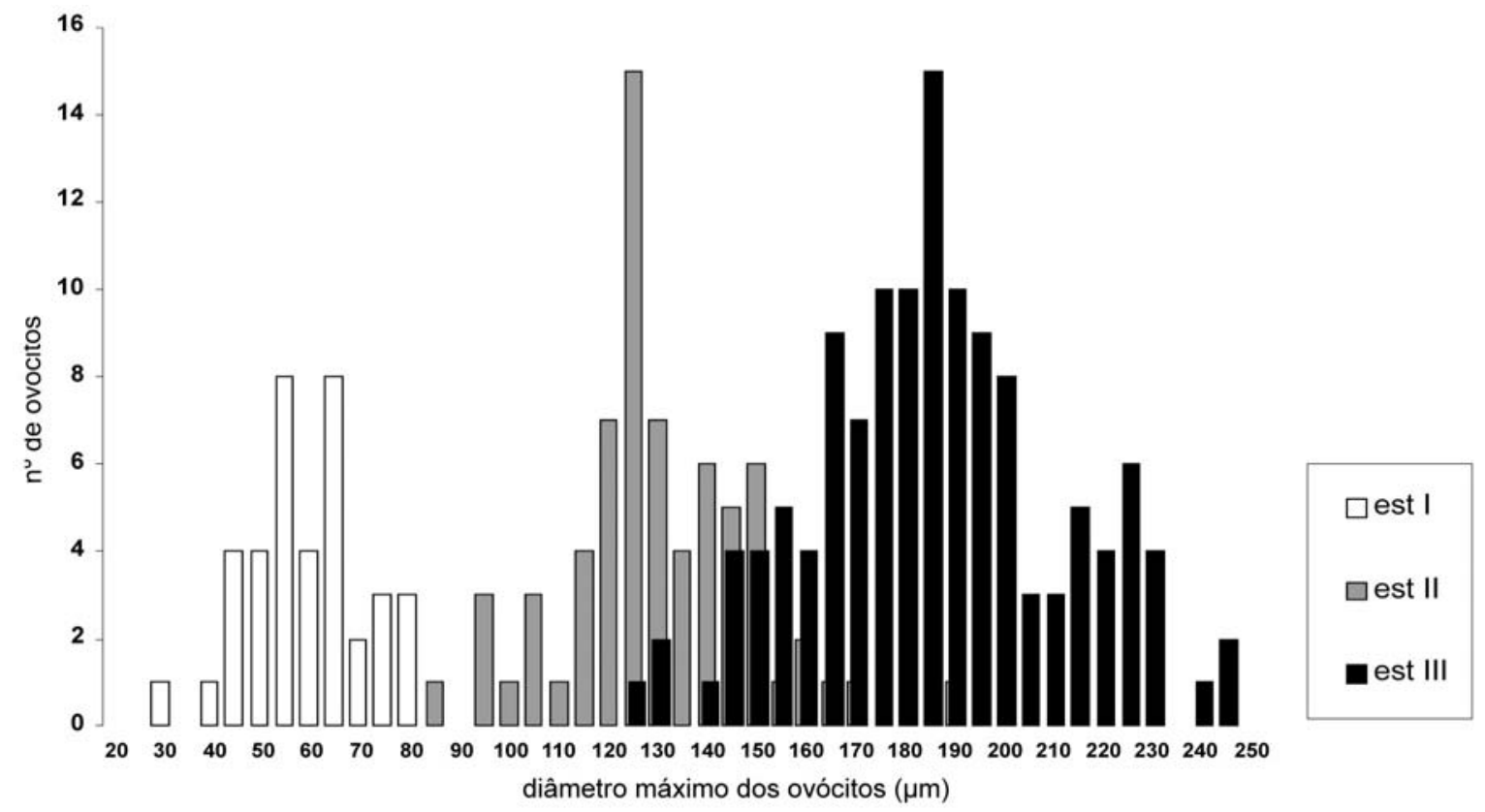

Fig. 5. Distribuição de freqüência dos diâmetros celulares para os três diferentes estágios de desenvolvimento dos ovários das fêmeas de Artemesia longinaris. 
Tabela II. Diâmetro médio, amplitude dos diâmetros e resultado da ANOVA, contendo SQ (soma dos quadrados), GL (graus de liberdade) e QM (quadrado médio). O teste de Tukey mostrou diferença significativa entre os diâmetros médios dos ovócitos* ao nível de significância $(\mathrm{p}<0,05)$. Os pré-requisitos de normalidade $(\mathrm{K}-\mathrm{S}<0,2)$ e homocedasticidade (Levene $>0,05$ ) foram atendidos.

\begin{tabular}{cccccc}
\hline \multicolumn{5}{c}{ ANOVA } \\
\hline Efeito & SQ & GL & QM & F & p \\
\hline $\begin{array}{c}\text { Estágio de maturação } \\
\text { erro }\end{array}$ & 498912 & 2 & 249456 & 534,022 & 0,00 \\
& 107906 & 231 & 467 & & \\
\hline
\end{tabular}

\begin{tabular}{crcccc}
\hline & \multicolumn{5}{c}{ Tukey } \\
\hline Estágio de maturação & média & amplitude & & K-S & Levene \\
\hline I & 56,97 & $28,32-79,9$ & I-II* & 0,01 & 0,086 \\
II & 127,68 & $82,23-186,6$ & II-III* & & \\
III & 183,08 & $120,3-242,8$ & III-I* & & \\
\hline
\end{tabular}

\section{DISCUSSÃO}

Os resultados da análise histológica mostraram que a classificação macroscópica da gônada feminina, baseada na coloração e no tamanho, está intimamente relacionada com o desenvolvimento e com a organização das células do ovário. Dessa forma, foi possível estabelecer uma escala prática de uso em laboratório para classificação rápida das gônadas de $A$. longinaris. Esse método foi amplamente utilizado por autores que realizaram estudos, tanto de dinâmica reprodutiva, quanto em experimentos de aqüicultura (VogT et al., 1989; CASTILLE \& LaWrence, 1991; Quinitio \& Millamena, 1992; Medina et al., 1996; Palacios et al., 1999).

Ao contrário das escalas macroscópicas desenvolvidas para Penaeus monodon (Fabricius, 1798) (TAn-Fermin, 1991) e F. brasiliensis (Quintero \& Gracia, 1998), que classificaram o estágio de maturação a partir da gônada dissecada, o presente estudo baseou-se em características observadas através do exoesqueleto, facilitando o trabalho em laboratório. A única limitação deste método é a dificuldade em diferenciar o estágio I (imaturo) do IV (desovado), já que macroscopicamente são muito parecidos. No entanto, o número de fêmeas identificadas através de cortes histológicos em estágio IV é muito pequeno, pois observou-se que o ovário da espécie possui alta capacidade de recuperação, evoluindo rapidamente para o estágio I após a desova (ScELzo, 1991). A dificuldade de coleta de indivíduos em estágio IV no ambiente fez com que Christiansen \& Scelzo (1971) mantivessem algumas fêmeas em cativeiro até a desova para que o ovário pudesse ser caracterizado histologicamente. Devido à baixa freqüência do estágio IV no ambiente, a classificação da gônada através do exoesqueleto é a mais indicada para $A$. longinaris.

Inicialmente, uma fonte de erro na classificação macroscópica do desenvolvimento dos ovários de $A$. longinaris pode surgir na separação dos estágios II (maturação incipiente) e III (maduro). Durante estes estágios a gônada ocupa grande parte do cefalotórax e da cavidade abdominal, além do fato de que a variação de tons é grande. A análise microscópica elimina a possibilidade de confusão entre os estágios, atribuindo a coloração verde-escura ao estágio III e verde-neutra ao estágio II. Pode-se dizer que a escala cromática de classificação dos estágios de desenvolvimento gonadal de $A$. longinaris é uma importante ferramenta para os estudos populacionais, permitindo avaliar com maior acurácia a dinâmica reprodutiva da espécie e, conseqüentemente, o status em que a população se encontra.

Grande parte dos autores divide o desenvolvimento gonadal microscópico em 5 estágios (imaturo, em desenvolvimento, maturação incipiente, maduro e desovado) (Vogt et al., 1989; Castille \& Lawrence, 1991; Tan-Fermin, 1991; Medina et al., 1996; Quintero \& Gracia, 1998; Palacios et al., 1999). Os estágios I (imaturo) e II (em desenvolvimento) não mostram diferença significativa, tanto no diâmetro celular, quanto nas características estruturais e químicas dos ovócitos (Quintero \& Gracia, 1998). Devido a esse fato, foram considerados apenas 4 estágios de desenvolvimento celular dos ovários de $A$. longinaris, unindo os estágios I (imaturo) e II (em desenvolvimento) propostos por outros autores. Outro argumento a favor da união desses dois estágios é o fato de se apresentarem macroscopicamente idênticos, além de, biologicamente, o ovário estar na fase de repouso, em ambos.

As mudanças observadas nos ovários do estágio I (imaturo) para o estágio II (maturação incipiente) são muito bem-marcadas. Segundo QuACKenBush (1991), as células aumentam drasticamente em tamanho e peso, pois iniciam a produção de vitelo. Como conseqüência desta produção, o citoplasma passa a ser acidófilo, apresentando afinidade por corantes ácidos (eosina) (Bell \& Lightner, 1988).

As células em estágio III da espécie mostraram uma diferença marcante em relação a outros peneídeos, onde normalmente são verificados corpúsculos periféricos bem formados ao redor do citoplasma (cortical rods) (BELL \& LightNer, 1988). No camarão $A$. longinaris não foram observados cortical rods, mas apenas um aumento no tamanho dos grânulos, que durante esse estágio migram para a periferia da célula, fato também verificado por Christiansen \& Scelzo (1971). Segundo Bell \& Lightner (1988), o deslocamento dos grânulos para a periferia do citoplasma está relacionado com a liberação de uma substância responsável pelo recobrimento externo do ovo após a desova.

Foram considerados em atividade reprodutiva apenas indivíduos em estágio III (maduro) (equivalente ao estágio IV de Vogt et al., 1989; CASTille \& LaWrence, 1991; TAN-Fermin, 1991; Medina et al., 1996; Quintero \& Gracia, 1998; Palacios et al., 1999). No entanto, alguns autores dividem os estágios de maturação em dois grupos, maduros e imaturos, baseando-se em análises estatísticas do diâmetro médio dos ovócitos (Quintero \& GRACIA, 1998), considerando como reprodutivas as fêmeas que apresentam os ovários em maturação incipiente e os maduros. Considerar as fêmeas de $A$. longinaris com ovários em maturação incipiente (estágio II) como reprodutivas, geraria um comprimento médio de primeira maturação demasiadamente baixo, podendo afetar a administração do recurso.

O estágio IV (desovado) foi verificado apenas em fêmeas coletadas na isóbata dos 20 metros. Apesar da baixa captura neste estágio, pode-se inferir que a desova acontece em torno desta profundidade, concordando com 
o observado por Boschi (1969) na Argentina.

Os diâmetros médios dos ovócitos de A. longinaris mostraram grande similaridade com outros resultados obtidos para a espécie (Christiansen \& SCELzo, 1971), assim como para outros peneídeos, inclusive no que diz respeito à sobreposição de diâmetros entre os dois últimos estágios de maturação (GuitarT \& Quintana, 1978; RAMOS \& TORRAS, 1986). A distribuição polimodal, aliada à coexistência de ovócitos nas três fases de desenvolvimento, corroboram a hipótese de desova parcial da espécie verificada na Argentina (Scelzo, 1991; Petriella \& Bridi, 1992). A espécie produz desovas múltiplas durante o período de intermuda, para o qual requer apenas uma única impregnação (SCELzo, 1991). O mesmo autor ressaltou que a taxa de impregnação é alta e não depende do estágio de desenvolvimento dos ovários. Essa estratégia reprodutiva também foi verificada para outros peneídeos em estudos populacionais, entre eles Penaeus kerathurus Forskal, 1775 (Rodriguez, 1981) e Penaeus latisulcatus Kishinouye, 1896 (Penn, 1980).

Agradecimentos. À Secretaria de Ciência e Tecnologia do Estado do Rio Grande do Sul, pelo suporte financeiro através do Programa de Pólos Tecnológicos.

\section{REFERÊNCIAS BIBLIOGRÁFICAS}

Bell, T. A. \& Lightner, D. V. 1988. A handbook of normal penaeid shrimp histology. Baton Rouge, World Aquaculture Society. $107 \mathrm{p}$.

Boschi, E. E. 1969. Estudio biológico pesquero del camarón Artemesia longinaris Bate de Mar del Plata. Boletin del Instituto de Biologia Marina, Mar del Plata, 18:1-47.

Castille, F. L. \& Lawrence, A. L. 1991. Reproductive studies concerning natural shrimp populations: a description of changes in size and biochemical compositions of the gonads and digestive glands in penaeid shrimps. In: De LoACH, P. F.; Dougherty, W. J. \& Davidson, M. A. eds. Frontiers of shrimp research. Amsterdam, Elsevier. v.22, p.17-32.

Christiansen, H. E. \& Scelzo, M. A. 1971. Ciclo de maduración sexual y observaciones sobre la morfologia del aparato genital del camarón Artemesia longinaris Bate. Carpas, Mar del Plata, 16(5/D):1-22.

D'Incao，F. 1999. Subordem Dendrobranchiata (camarões marinhos). In: Buckup, L. \& Bond-Buckup, G. eds. Os camarões do Rio Grande do Sul. Porto Alegre, Editora da Universidade, p.271-299.

D'Incao, F.; Valentini, H. \& Rodrigues, L. F. 2002. Avaliação da pesca de camarões nas regiões Sudeste e Sul do Brasil; 1965-1999. Atlântica, Rio Grande, 24(2):49-62.

Guitart, B. \& Quintana, M. 1978. Estadios de maduración gonadal en las especies importantes del género Penaeus en el Banco del Campeche. Revista Cubana de
Investigaciones Pesqueras, Havana, 3:82-126.

Medina, A.; Vila, Y. et al. 1996. A comparative study of the ovarian development in wild and pond-reared shrimp, Penaeus kerathurus (Förskal, 1775). Aquaculture, Amsterdam, 148:63-75.

Palacios, E.; Rodríguez-Jaramillo, C. \& Racota, I. S. 1999. Comparison of ovary histology between different-sized wild and pond-reared shrimp Litopenaeus vannamei (=Penaeus vannamei). Invertebrate reproduction and development, Philadelphia, 35(3):251-259.

Pantone. 1999. Pantone Professional Color System. 14 $4^{\text {th }}$ ed. New Jersey, Carlstad. 260p.

Penn, J. W. 1980. Spawning and fecundity of the western king prawn, Penaeus latisulcatus in Western Australian waters. Australian Journal of Marine and Freshwater Research, Melbourne, 31:21-35.

Petriella, A. M. \& BRidi, R. J. 1992. Variaciones estacionales del ciclo de muda y la maduración ovárica del camarón (Artemesia longinaris). Frente Maritimo, Montevideo, 11:85-92.

QuACKenbush, L. S. 1991. Regulation of vitellogenesis in penaeid shrimps. In: De Loach, P. F.; Dougherty, W. J. \& DAVIDSON, M. A. eds. Frontiers of shrimp research. Amsterdam, Elsevier. v.22, p.125-140.

Quinitio, E. T. \& Millamena, O. M. 1992. Ovarian changes and female-specific protein levels during sexual maturation of the white shrimp Penaeus indicus. The Israeli Journal of Aquaculture, Bamidgeh, 44(1):7-12.

Quintero, M. E. S. \& Gracia, A. 1998. Stages of gonadal development in the spotted pink shrimp Penaeus brasiliensis. Journal of Crustacean Biology, Lawrence, 18(4):680-685.

Ramos, L. \& Torras, E. 1986. Histologia del ovário maduro del camarón rosado Penaeus notialis com ablacion del pedúnculos oculares. Revista de Investigaciones Marinas, Havana, 7:53-61.

Rodriguez, A. 1981. Growth and sexual maturation of Penaeus kerathurus (Förskal, 1975) serratus (Pennant) in salt ponds. Aquaculture, Amsterdam, 24:257-266.

Scelzo, M. A. 1991. Copula en cautiverio y desove del camaron Artemesia longinaris Bate, 1988 (Decapoda, Penaeidae). Informe Tecnico de Ciencia Marina, Barcelona, 164:1-16.

Tan-Fermin, J. D. 1991. Effects of unilateral eyestalk ablation on ovarian histology and oocyte size frequency of wild and pond-reared Penaeus monodon (Fabricius) broodstock. Aquaculture, Amsterdam, 93:77-86.

Valentini, H.; D'Incao, F. et al. 1991. Análise da pesca do camarão-rosa (Penaeus paulensis e Penaeus brasiliensis) nas regiões sudeste e sul do Brasil. Atlântica, Rio Grande, 13(1): $143-157$

Vogt, G.; Quinitio, E. T. \& Pascual, F. P. 1989. Interaction of the midgut gland and the ovary in vitellogenesis and consequences for the breeding success: a comparison of unablated and ablated spawners of Penaeus monodon. In: De Pauw, J. N.; Ackefors, H.; Wilkins, N. E. eds. Aquaculture. A biotechnology in progress. Bredene, European Aquaculture Society. p.581-592.

ZAR, T. H. 1984. Biostatistical analysis. New Jersey, Prentice Hall. 718p.

Recebido em julho de 2003. Aceito em setembro de 2004. ISSN 0073-4721 
Erro na original impressa. No título, o termo "Penaeidae" foi substituído por "Palaemonidae" 